\title{
Belief, credence, and moral encroachment
}

\author{
James Fritz ${ }^{1}(\mathbb{C})$ Elizabeth Jackson ${ }^{2}[\mathbb{C}$
}

Received: 30 April 2019 / Accepted: 16 July 2020 / Published online: 28 July 2020

(C) Springer Nature B.V. 2020

\begin{abstract}
Radical moral encroachment is the view that belief itself is morally evaluable, and that some moral properties of belief itself make a difference to epistemic rationality. To date, almost all proponents of radical moral encroachment hold to an asymmetry thesis: the moral encroaches on rational belief, but not on rational credence. In this paper, we argue against the asymmetry thesis; we show that, insofar as one accepts the most prominent arguments for radical moral encroachment on belief, one should likewise accept radical moral encroachment on credence. We outline and reject potential attempts to establish a basis for asymmetry between the attitude types. Then, we explore the merits and demerits of the two available responses to our symmetry claim: (1) embracing radical moral encroachment on credence and (2) denying radical moral encroachment on belief.
\end{abstract}

Keywords Belief $\cdot$ Credence $\cdot$ Moral encroachment $\cdot$ Epistemic rationality

\section{Introduction}

Belief is a familiar attitude: believing something is taking it to be the case or regarding it as true (Schwitzgebel 2019). You might believe that the earth is round, that $1+1$ $=2$, or that it will rain tomorrow. But you're probably more confident that $1+1=2$ than that it will rain tomorrow, even if you believe both things. For this reason, many

James Fritz and Elizabeth Jackson contributed equally to this article.

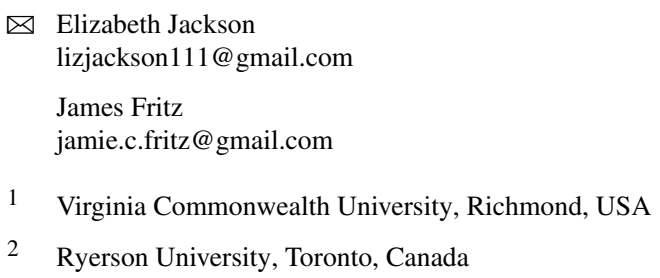


epistemologists appeal to a second attitude, called credence. Credences are often given a value on the $[0,1]$ interval. 0 represents maximal confidence some proposition is false, and 1 represents maximal confidence some proposition is true. You probably have a credence close to 1 that $1+1=2$, but a lower credence that it will rain tomorrow (maybe 0.9 , if there's a $90 \%$ chance of rain).

Why think we have both beliefs and credences? A popular idea is that belief and credence play different roles, and these roles are indispensable to our mental, epistemic, and/or practical lives. For instance, credences can represent subtle differences in our epistemic situation that beliefs cannot (e.g. the difference between your attitude toward the mathematical proposition and the proposition about rain). Further, beliefs might play a role in knowledge that credences do not (Staffel 2019). Finally, belief that $\mathrm{p}$ is a settled commitment to the truth of $p$. However, credence (with the exception of credence 0 and 1) keeps possibilities open; a high credence in $p$ is not necessarily a commitment to the world's being such that $\mathrm{p}{ }^{1}$

While we think it is plausible belief and credence have distinct roles, we do not assume that belief and credence are metaphysically irreducible to each other. Just as Superman and Clark Kent might in some sense play different roles but ultimately be identical, belief and credence might in some sense play different roles even if, e.g. belief is reducible to credence. ${ }^{2}$ So our assumption that belief and credence play different roles is consistent with both reductionist and non-reductionist views. Further, it's a fair assumption for dialectical purposes. Our ultimate goal is to argue against several views on which belief and credence, at least, play different normative roles-on which, e.g. one attitude is apt for moral or rational criticism in a way the other isn't. If the two states play different roles, that only helps our opponents' case for asymmetry.

In this paper, our main concern isn't ontological questions about what mental states exist, but rather normative questions about what makes mental states rational. ${ }^{3}$ On this matter, here is a natural thought:

Purism: the epistemic rationality of a belief that $\mathrm{p}$ or a credence in $\mathrm{p}$ is solely a function of factors related to the truth of $p$.

According to purists, the rationality of beliefs and/or credences is determined by things like evidence, reliability, or other factors that bear on the truth of the proposition in question. Recently, however, some have challenged purism. ${ }^{4}$ One way to resist purism

\footnotetext{
${ }^{1}$ See Nagel (2010: p. 418), Ross and Schroder (2014: pp. 275-277), Staffel (2017), and Jackson (2019a). For an overview of the belief/credence relationship, see Jackson (2020).

2 Our assumption nonetheless rules out eliminativist views of belief and credence, such as those defended by Churchland (1981), Stich (1996), and Maher (1993: pp. 152-155).

${ }^{3}$ While much of the original pragmatic encroachment debate was about knowledge, most of the moral encroachment debate (with the exception of Moss 2018b) has proceeded in terms of rationality or justification. However, that doesn't mean that the moral encroachment debate, or our argument in this paper, has no implications for knowledge. It may be that practical or moral considerations affect knowledge by affecting justified belief. (The relationship between credence and knowledge is controversial, so if there is pragmatic or moral encroachment on credence, it is less clear what implications this would have for knowledge. See Moss (2018a, b)).

${ }^{4}$ For a related notion of purism, see Fantl and McGrath (2009: pp. 27-28). Roeber (2018) points out that pragmatic and moral encroachers aren't the only ones who deny that whether you should believe $\mathrm{p}$ only depends on factors relevant to the truth of $\mathrm{p}$.
} 
is to endorse moral encroachment. ${ }^{5}$ According to moral encroachment, moral features, unrelated to the truth of $p$, can make a difference to rational belief or credence that $p$. So, to take an example from Basu (2019b), suppose you have good (albeit perhaps misleading) evidence that people of a certain race are frequently bad tippers. Some prominent advocates of moral encroachment argue that it is irrational to believe, on the basis of this evidence alone, that a particular member of the relevant racial group is a bad tipper, and that this is irrational precisely because racial profiling is morally objectionable. Moral considerations thus might make a difference not only to a belief's desirability, or its all-things-considered goodness, but to its rationality.

More specifically, this is not a claim about all-things-considered rationality, but about epistemic rationality. The claim is that the moral encroaches on the epistemic; moral stakes don't just make a difference to rationality in general, but to epistemic rationality in particular. ${ }^{6}$

To date, almost all proponents of moral encroachment hold that there is an asymmetry between rational belief and rational credence. That is, they maintain that the moral can make a difference to rational belief, but not to rational credence. In this paper, our goal is to show that the most prominent defenses of moral encroachment lack the tools to defend this asymmetry thesis. We proceed as follows. In Sect. 2, we distinguish between moderate and radical versions of moral encroachment on belief, and we outline the most prominent arguments for the latter sort of encroachment. In Sect. 3, we argue that, insofar as one accepts the arguments outlined in Sect. 2 for radical moral encroachment on belief, one should likewise accept radical moral encroachment on credence. In Sect. 4, we consider the virtues and vices of the two epistemological views that our argument leaves open: one that embraces radical moral encroachment on both belief and credence, and one that rejects radical moral encroachment on both. While our ultimate goal is to argue for a conditional claim, we conclude by offering some reasons to prefer the view that rejects radical moral encroachment on both attitudes.

\section{Radical moral encroachment}

This section distinguishes between moderate and radical moral encroachment. It then surveys the most prominent arguments in favor of radical moral encroachment.

\subsection{Moral encroachment: moderate versus radical}

The core claim of moral encroachment, we've seen, is that certain moral facts can play a surprising difference-making role in epistemology. But which moral facts play this role?

Some defenders of moral encroachment answer this question by appealing to moral facts about agents' actions and options. Consider an example: suppose that a ship-

\footnotetext{
5 For discussions of moral encroachment, see Pace (2011), Fritz (2017), Gardiner (2018), Moss (2018b), Schroeder (2018b), Basu and Schroeder (2019), Basu (2019a, b), Bolinger (2020, forthcoming).

6 Our focus here is on moral encroachment on epistemic rationality, but we take our arguments to apply equally to questions about epistemic justification (if there is a difference). Further, by 'rationality' we mean epistemic rationality unless otherwise specified.
} 
builder sends a passenger vessel out to sea even though her total evidence only makes it $85 \%$ likely that the ship is seaworthy. ${ }^{7}$ The shipbuilder acts wrongly, and is blameworthy for acting on the basis of such a weak body of evidence. On a moral-encroachment view, these moral facts about action might partly explain an epistemic fact: that the shipbuilder is not in a position to rationally believe that the ship is seaworthy.

Some recent defenses of moral encroachment, however, look beyond moral facts concerning actions and options, and call attention to the moral status of belief itself. Basu and Schroeder (2019: sec. 1), for instance, argue that we can morally wrong others simply by forming beliefs about them; Pace (2011: p. 264) suggests that belief in God might be "intrinsically" morally valuable. These are meant to be examples of beliefs that are morally objectionable (or morally valuable) independent of their implications for action. Basu, Schroeder, and Pace argue that epistemic norms are sensitive to moral facts of this sort.

The latter sort of moral encroachment, unlike the former, represents a significant departure from the broader pragmatic-encroachment literature. The most prominent defenses of pragmatic encroachment, including Stanley (2005), Hawthorne and Stanley (2008), and Fantl and McGrath (2009), all explicitly draw connections between rational belief and the normative status of actions or options. We'll therefore call the following claim

Moderate Moral Encroachment: Whether a person's belief that $\mathrm{p}$ is rational can depend on moral facts about her actions or options-including moral facts that do not bear on whether $\mathrm{p}$.

Traditional defenses of pragmatic encroachment, however, do not draw connections between epistemic rationality and the moral status of belief itself. We'll therefore call the following claim

Radical Moral Encroachment: Whether a person's belief that $\mathrm{p}$ is rational can depend on moral facts about her belief itself (where these facts are not merely derivative of facts about her actions or options) — including even moral facts that do not bear on whether p. $^{8}$

One could, in principle, defend radical moral encroachment without also defending moderate moral encroachment. What's more, one can defend both moderate and radical moral encroachment; in fact, Schroeder (2012, 2018b) does so. To defend both moderate and radical moral encroachment is to claim that epistemic norms are sensitive to (at least) two different sorts of moral properties: moral properties of actions and options, and moral properties of beliefs themselves.

\footnotetext{
7 Pace (2011: p. 257) draws on Clifford's (1886: p. 346) example of a shipbuilder to make a case for moral encroachment on epistemic justification.

8 This distinction between moderate and radical moral encroachment first appears in Fritz (2019). The distinction also appears (sometimes under a different name) in the taxonomies offered by Gardiner (2020) and Bolinger (forthcoming). Note that radical moral encroachers need not take on a commitment that Moss (2018b: p. 915) describes as both radical and unattractive: the commitment that even moral considerations that do not depend on the truth or falsehood of belief can make a difference to that belief's epistemic status. Schroeder (2018b) rejects this commitment; Basu accepts it. For further discussion, see Fritz (2019).
} 


\subsection{A case for radical moral encroachment}

Why think that there is radical moral encroachment in epistemology? The most prominent recent defenses of radical moral encroachment, found in Basu and Schroeder (2019) and Schroeder (2018b), motivate the view by appealing to a range of real and imagined cases. ${ }^{9}$

The cases that motivate Basu and Schroeder, generally, fall into two groups. The first group of cases involves morally fraught beliefs in the context of close personal relationships. Consider a person who believes on the basis of strong but inconclusive evidence that her spouse, who is just returning home with a wine stain on her shirt, has started drinking again. ${ }^{10}$ The second group of cases involves beliefs formed on the basis of statistical regularities in demographic groups. A case that falls into this second group is the example of John Hope Franklin, which Basu and Schroeder draw from Gendler (2011). Franklin is

... an African-American member of an elite social club in Washington DC who is mistaken for staff by a fellow club member. In this case, the evidence that is possessed by the club member who forms the belief that John Hope Franklin is staff is quite good, in probabilistic, purely truth-directed terms, in comparison to many cases of ordinary beliefs that we form on an ordinary basis, because the club's members are nearly all white, and its staff is nearly all black. (Basu and Schroeder 2019: sec. 3.2)

Basu and Schroeder make two distinctive claims about beliefs like these. First: in these cases, the belief itself wrongs someone. Second: in these cases, the belief is not only morally deficient but also epistemically deficient.

What motivates the first of these claims - that a belief can wrong someone? First, Basu and Schroeder note that there is something intuitively objectionable about the beliefs that concern them. The subjects of these beliefs are apt to feel hurt, wounded, or wronged (Basu 2019a: sec. 1). Further, they are apt to feel that they are owed an apology, which Basu and Schroeder deem "the sign of a directed wrong" (2019: sec. 1.1). Basu and Schroeder also note, in multiple contexts, that the reasoning on display in the John Hope Franklin case (and structurally similar cases) is racist reasoning (see Schroeder 2018a: sec. 3.2; Basu 2019b). These three points (about the feeling of having been wronged, about apology, and about racism) provide a prima facie case in favor of the view that these cases involve moral wrongdoing of some sort.

Next, Basu and Schroeder argue that the directed wrongs in these cases arise, at least in part, from belief itself. We can owe apologies, they argue, not only for character traits and reasoning processes that dispose us to believe (Basu 2019b: sec. 3-4), and not only for the actions or assertions that arise from our beliefs, ${ }^{11}$ but also for beliefs themselves. This amounts to a prima facie case that belief itself can morally wrong.

\footnotetext{
${ }^{9}$ Since Michael Pace's endorsement of radical moral encroachment is quite tentative (2011: p. 264), we set his view aside for the sake of exposition, returning to it in Sect. 3.3.

10 This case appears in Basu and Schroeder (2019) and Basu (2019a). For related cases, see Keller (2004) and Stroud (2006).

11 See Basu's Security Guard case (2019b: sec. 2).
} 
What is it about beliefs like the club member's that make them morally objectionable? The arguments in favor of doxastic wronging do not rest on any particular answer to this question, but advocates of moral encroachment have suggested several possible lines of response. First, Schroeder (2018b) suggests that some beliefs diminish others. ${ }^{12}$ Diminishment, for Schroeder, does not always involve seeing someone in a negative light, but can also involve "bringing someone down" in a way that minimizes their agential contribution (2018b: p. 124). If you form the belief that your neighbor is good at math because she is Asian, for instance, your belief might "bring her down" by downplaying the significance of her agency. In other cases, Schroeder suggests, a belief might minimize an agent's contribution by making it out to be less of a contribution, or by making it out to be a worse contribution.

Second, consider the possibility that a belief can wrong someone when it amounts to taking up an objectionable stance toward her. Strawson (1962) distinguishes two ways we can view others: the objective stance and the participant stance. The objective stance characterizes others as objects to be "managed or handled." The participant stance, on the other hand, is the stance we take in most of our interpersonal relations, and it is characterized by reactive attitudes such as gratitude and resentment. When we take the participant stance toward someone, we see them as a moral agent. Basu (2019a) and Marušić and White (2018) argue that all wronging beliefs involve taking the objective stance toward those who are wronged. For example, when the club member believes John Hope Franklin is a staff member, the club member treats John Hope Franklin as an object, and "observe[s] him in the way a scientist observes the planets" (Basu 2019a: p. 924). Perhaps this belief wrongs Franklin, in part, because the club member neglects his personhood and fails to respect him as a moral agent.

These two lines of explanation raise a number of tricky questions. For instance: Basu, Marušić, and White all acknowledge that, in some cases, taking the objective stance toward a person is entirely morally unproblematic. This means that, in Basu's words, the full story about doxastic wronging is "more multifaceted and complicated than the simple imperative to relate to others as people [rather than objects]" (2019a: p. 929). ${ }^{13}$ But Basu, Marušić, and White do not attempt to explain precisely when it's problematic to take up the objective stance. We are not convinced that the full story here can be told in a satisfactory way. Nor, indeed, are we convinced that mere belief can ever morally wrong a person. But, for the sake of argument, we will grant the picture that has been sketched so far.

Suppose that certain beliefs (like the club member's belief about John Hope Franklin) are morally deficient. What should we say about the epistemic status of those beliefs? As Basu and Schroeder emphasize in the long quotation above, beliefs that wrong others are sometimes supported by evidence that, in "probabilistic, purely truth-directed terms," is “quite good" (2019: sec. 2). What's more, it seems possible to

\footnotetext{
12 Schroeder claims that doxastic wronging only occurs in cases where a false belief diminishes someone. We'll set this complication aside.

13 Compare Marušić and White (2018: p. 108). Schroeder (2019) offers an attempt to distinguish between problematic and unproblematic cases of seeing others "as objects".
} 
imagine that the relevant beliefs might be appropriately based on that strong evidence. Possibly, some beliefs that wrong others could be entirely epistemically rational. ${ }^{14}$

Basu and Schroeder reject this conclusion: they hold that no epistemically rational belief could be a case of wronging belief (2019: sec. 3.2; see also Schroeder (2019: sec. 1). Call this claim

No Tension for Belief: A belief that morally wrongs a person cannot be an epistemically rational belief.

Basu and Schroeder claim that No Tension for Belief enjoys intuitive support; indeed, they insist that the very idea of a belief that is both morally wrong and also rational in "every way required for knowledge" is "puzzling" (2019: sec. 3.2). They supplement these intuitive grounds for No Tension for Belief by offering an argument regarding apology. Apology for belief does not seem to be owed, Basu and Schroeder argue, in cases where standards of epistemic rationality have clearly been met. They illustrate this point by returning to the wine-stain case. They ask us to imagine the believer offering the following apology:

... 'well, I'm sorry for believing that you fell off the wagon, even though my belief was epistemically impeccable, short of being true'. This does not seem to us to be much of an apology. And the reason why it does not seem to be much of an apology, it seems to us, is that satisfying every epistemic standard appropriate to belief short of truth looks like the right kind of thing to defeat any presumption of being a wrong. (2018, sec. 3.2)

Suppose that epistemically rational beliefs never constitute moral wrongings. How can we explain this? After all, we've granted that there is powerful evidence in favor of some beliefs that morally wrong others. Basu and Schroeder suggest an explanation through radical moral encroachment. If standards of epistemic rationality are sensitive to moral facts, then we can explain why it takes an unusually high degree of epistemic support to rationally believe that one's spouse has started drinking again-precisely by appealing to the moral risk of wronging her through forming that belief.

In short, Basu and Schroeder argue for radical moral encroachment through three steps. First, they argue that some beliefs morally wrong others. Second, they argue that those beliefs could not also be epistemically rational. Finally, they argue that the best way to explain why the relevant beliefs are epistemically irrational is through an appeal to radical moral encroachment.

\section{Radical moral encroachment on credence}

So far, we've discussed the claim that there is radical moral encroachment on belief. But we haven't yet considered a closely related claim:

\footnotetext{
14 Indeed, it's striking that Gendler (2011: p. 57) discusses the John Hope Franklin case precisely to illustrate the notion that morality sometimes requires "explicit irrationality through base-rate neglect." Cf. Schroeder (2019: sec. 1).
} 
Radical Moral Encroachment on Credence: Whether a credence in $p$ is epistemically rational can depend on moral facts about the credence itself-including even moral facts that do not bear on whether $\mathrm{p}$.

Our goal in this paper is to show that the most prominent form of argument for Radical Moral Encroachment on Belief supports Radical Moral Encroachment on Credence as well. Our discussion will therefore be structured around the following argument:

1. There is radical moral encroachment on belief.

2. If there is radical moral encroachment on belief, then there is radical moral encroachment on credence.

3. Thus, there is radical moral encroachment on credence.

In this section, we defend premise 2 , which posits symmetry between belief and credence. In 3.1, we show that the existing arguments for moral encroachment on belief apply to credence. In 3.2, we go beyond the existing arguments, and examine and reject a number of possible ways one might argue for a belief/credence asymmetry. Of course, this doesn't mean that there is no in-principle way one might resist premise 2 , but the current literature does not suggest a plausible way of doing so. This means that those who accept premise 1, including Basu and Schroeder, face pressure to accept the argument's conclusion.

This is a striking result, in part because the defenders of radical moral encroachment uniformly reject radical moral encroachment on credence. For example, Pace (2011: p. 255) accepts degree-of-confidence evidentialism "for present purposes," on the grounds that it's "plausible." Ross and Schroeder (2014: p. 273) commit to a nonreductionist view of belief in credence in part because they think it is the best way to affirm encroachment on belief without commiting to encroachment on credence. In a later paper, Schroeder (2018a: sec. 2.1) makes two points against encroachment on credences. First, it would make one vulnerable to Dutch Books. Second, it's not motivated by the considerations that motivate traditional pragmatic encroachment. Finally, Basu has confirmed in conversation that she rejects radical moral encroachment on credence.

In fact, as far as we know, there are no defenders of radical moral encroachment on credence. There are two notable discussions of credal encroachment. Gao (2019) defends a descriptive view on which practical stakes affect credence. Moss (2018a, b) defends a sort of moral encroachment on credences, but it concerns knowledge rather than epistemically rational credence. What's more, Moss does not endorse radical moral encroachment of any sort (2018b: p. 196).

Defenders of radical moral encroachment on belief, then, uniformly reject radical moral encroachment on credence. What justifies this asymmetry? Surprisingly, there are few extant arguments for the asymmetry. In many cases, the asymmetry is asserted rather than argued for (Pace; Ross and Schroeder). While Schroeder (2018a) points out that credal moral encroachment could make one vulnerable to Dutch Books, he also notes that moral encroachment on belief may also make one vulnerable to Dutch Books, so this likely isn't a promising basis for the asymmetry. (We discuss moral encroachment and Dutch Books further in Sect. 4.2). Other authors (like Basu) focus on belief and discuss credence only in passing. Thus, while radical moral encroachment on credence is rejected across the board, the motivation for treating it differently than 
belief is not clear. Part of the goal of this paper, then, is to consider (but ultimately reject) potential justifications for accepting radical encroachment on belief, but not on credence.

Moral encroachment on credence suggests that, although it's generally epistemically rational to match one's credences to degrees of epistemic probability, that rule of thumb could be overridden by moral facts in certain cases. This is a puzzling proposal, and it raises tricky questions. Perhaps most pressing: in cases where epistemic rationality forbids having the credence that matches one's level of epistemic probability, what is the epistemically rational credence? Our arguments in what follows will not presuppose any particular answer to this question. A natural suggestion is that in certain morally-loaded cases, it is epistemically rational to set aside, or treat as inadmissible, some of one's evidence (e.g. evidence about base-rates in certain reference classes). On this proposal, the epistemically rational credence is the credence supported by one's overall epistemic position, minus the offending evidence. ${ }^{15} \mathrm{We}$ do not aim to show that this heterodox proposal is ultimately worth accepting; our goal is to establish that the arguments for radical moral encroachment on belief provide the materials for analogous arguments for radical moral encroachment on credence.

\subsection{Translating the arguments to credences}

In Sect. 2, we considered two kinds of cases that are generally used to motivate radical moral encroachment. The first sort of case involves close personal relationships-e.g. the wine stain case. The second involves beliefs based on statistical generalizations-e.g. the case of John Hope Franklin. Consider alternative versions of these cases, that don't involve forming beliefs, but instead merely involve forming credences. For instance, your wife comes home with a wine stain on her shirt, and you form a high credence that she has started drinking — say, somewhere around 0.9. Nonetheless, you don't believe she has started drinking. Or imagine a club member who doesn't form an outright belief John Hope Franklin is a staff member, but is nonetheless quite confident, forming a high credence that John Hope Franklin is a staff member. The arguments for moral encroachment on belief apply equally to these high-credence-only cases. Or so we will argue.

Consider Basu and Schroeder's first argument-that there is something intuitively objectionable about the beliefs featured in these cases. These intuitions are not, of course, universally shared. But those who feel their force will also likely find something intuitively objectionable about merely forming high credences in these cases. ${ }^{16}$ Imagine telling your wife, after seeing the wine stain, 'I'm quite confident you've begun drinking again. I don't full-out believe it, but I think there's a very high probability it is true. While I'm not totally certain, I strongly suspect that you've been

\footnotetext{
15 Two other options: the radical encroacher might say that epistemic rationality sometimes admits of dilemmas, such that no matter what a believer does, her credal state will be epistemically irrational. Or she might say that, in certain cases, epistemic rationality requires us to take on imprecise credences. Thanks to an anonymous referee for encouraging us to offer more detail here.

16 For other endorsements of this claim, see Enoch and Spectre (ms) and Gardiner (2018: p. 179), who writes that "some of Schroeder and Basu's motivations for moral encroachment extend to moral encroachment about beliefs representing what is likely".
} 
behaving in a way that's harmful to yourself and to our relationship." This strikes us as intuitively objectionable - almost as intuitively objectionable as forming a belief in her failure.

Something similar can be said about the John Hope Franklin case. Basu and Schroeder claim that the club member's belief about John Hope Franklin is morally objectionable racist reasoning. But merely forming a high credence that John Hope Franklin is a staff member on the basis of his race also seems like racist reasoning. Generally, we needn't know that a person has formed an outright belief in order to know that she has engaged in objectionable racial profiling.

Schroeder and Basu's apology argument can also be applied to credences. Basu and Schroeder take intuitions about when an apology is owed very seriously. If an apology for $\mathrm{P}$ would be insufficient, they take this to suggest that $\mathrm{P}$ is not the full story about what needs to be apologized for. Apologizing for acting on a belief, they argue, often doesn't seem to be sufficient; intuitively, one must also apologize for having the belief itself. That wouldn't make sense unless something about the belief itself wronged me (Basu and Schroeder 2019: sec. 1.1). The club member who profiles John Hope Franklin, for instance, can't escape the demand for apology by noting that she didn't act on the belief.

But in the case where a club member merely forms a high credence that John Hope Franklin is a staff member, it likewise seems like she can't escape a demand for apology simply by noting that she didn't form an all-in belief. It would be completely inappropriate for someone to respond to a charge of racial profiling by saying, "Ah, yes, but have you heard of the belief/credence distinction? I was merely extremely confident that you were a valet; I didn't believe! So I've done entirely right by you, and I owe you no apology." This is an unsatisfactory way to escape a demand for apology. We maintain that insofar as one ought to apologize for beliefs in these cases, one is equally obliged to apologize for high credences, even if those credences track the evidence.

Consider next two explanations that Basu and Schroeder suggest as to precisely why beliefs can wrong: a story about "diminishment," and a Strawsonian story about the objective stance. We've expressed reservations about both of these stories, but to the extent that they succeed, they motivate that credences alone can wrong. Let's start with Schroeder's (2018b) argument that wronging beliefs diminish. These beliefs, Schroeder suggests, make a person's agential contribution out to be either a less significant or a worse contribution. By engaging in racial profiling, for instance, a person might view another as a predictable product of social forces-as someone whose intellectual achievements are not genuinely the product of her agency.

The same moral worries arise in cases of mere high credences formed through racial profiling. Suppose, for instance, that I know almost nothing about my neighbor, but I become highly confident that she is good at math, solely on the basis of my belief that members of her race are very often good at math. When I do so, I am allowing my picture of her abilities to be primarily (albeit perhaps not fully) shaped by my picture of broader social forces, and not by her agency. Similar points can be made about beliefs that make an agent's contribution out to be not less significant but worse. If a belief that one's wife has fallen off the wagon paints her agency in an objectionably negative light, a very high credence that one's wife has fallen off the wagon seems apt to do 
the same. This is not to say that mere credence is always as objectionable as outright belief would be. But this difference in the seriousness of doxastic wronging does not raise any problems for the point we are making here: namely, that the moral objections that Schroeder raises to diminishing beliefs are perfectly intelligible as objections to high credences.

Consider, now, the idea that beliefs can wrong when they embody a problematic stance, one that treats a person as an object rather than as an agent. Insofar as there is a coherent distinction to be drawn between the way we should form doxastic attitudes about mere objects and the way we should form doxastic attitudes about moral agents, it's entirely unclear why that story wouldn't apply to credences as well. Racial profiling that lacks outright belief can also involve taking up what Strawson's objective stance. Just as an astronomer can form credences about planets on the basis of statistical evidence, we can apply statistical evidence directly to an individual, and acquire a credence about them proportional to the statistic. Insofar as there is a moral requirement, in some cases, to regard others through the participant stance, our default assumption should be that this is a wholistic requirement-one that constrains both the beliefs and the credences we form about others.

It's worth pausing to consider an objection on behalf of the diminishment and objective-stance proposals. This objection starts from the thought that belief that $p$, unlike mere credence, "rules out" the possibility that not- $p$ (or views $p$ as correct, or settles the matter as to whether $p$ in her mind; see, e.g. Buchak 2014: p. 286). Mere credence, by contrast, does not rule anything out. It involves representing a given state of affairs as likely, but does not (at least, by itself) involve representing that state of affairs as obtaining. When a Cosmos Club diner becomes highly confident that John Hope Franklin is a staff member, but suspends judgment, she acknowledges two possible states of affairs (that he is a staff member and that he is not), but does not rule out either of the two. This might seem to help the defender of the diminishment proposal to justify an asymmetric approach to belief and credence. If I do not take a stand on what an agent is like, it might seem hard to see how my thinking about her can objectionably diminish her agential contribution. Similarly, maybe those who take up high credences do not thereby take up any stance at all, much less an objectionably impersonal one, toward other agents. ${ }^{17}$

We grant that this insight about the different natures of belief and credence may go some distance toward explaining why credence tends to wrong less severely than outright belief does. But we doubt that the best interpretation of either the diminishment or objective-stance proposal involves the assumption that doxastic wronging always involves representing some state of affairs as obtaining (rather than merely as likely). Let's take those proposals in reverse order.

The core idea behind the objective-stance proposal is that we can wrong others by taking up the objective stance toward them, mentally treating them as mere objects. But it's very plausible that one can take up the objective stance toward a person even if one solely represents her through credences. After all, we can surely approach actual mere objects in this way: solely forming credences, but never taking an outright stand about them. In fact, we can go further: some defenders of the objective-stance proposal claim

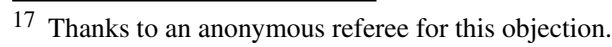


that restricting one's judgments about a person to credences is a paradigmatic way of giving up on the "participant stance." Marušić and White, for instance, illustrate the gap between the participant stance and the objective stance precisely by contrasting a case of outright belief based on testimony with a case in which one forms an "evidencebased prediction... that, given the kind of person they are and the circumstances they find themselves in, [one's interlocutor has] a 60\% chance of doing as they say" (2018: p. 110). Lara Buchak (2014) similarly suggests that credences alone cannot underwrite the reactive attitudes that characterize Strawson's participant stance. This suggests that, if the objective-stance account of doxastic wronging is on the right track, mere credences are just as apt to wrong as are outright beliefs-and perhaps even more so. At the very least, if there is a moral asymmetry between credence and belief, appeals to the objective stance alone cannot establish that asymmetry. It can only be established by the full story (which Basu, Marušić, and White do not attempt to tell) about precisely when the objective stance is morally problematic.

What about the diminishment proposal? Is it possible to diminish others' agential contributions without taking a stand? We think that, on any viable story about diminishment, it is. To see why, imagine a character who is generally doxastically cautious. He tends not to take a stand on how the world is in any arena, and his mental pictures of other people are probabilistic through-and-through. But he arrives at those probabilistic pictures through an uncharitable, agency-diminishing set of dispositions. He considers it next to impossible (but not impossible!) for anyone to escape the influence of social forces. As a result, he approaches any given stranger as extremely likely to be a walking, talking racial stereotype. Further, he always takes his information about even his closest friends to strongly (but fallibly!) support the ugliest, most despicable interpretation of their behavior. This character, by stipulation, never takes a stand on what people are like. And we can further stipulate that he always acknowledges that it's possible that any given person might, through a nearly-superhuman exercise of agency, defy the balance of probabilities. Even if we do so, Schroeder's complaints about diminishment are entirely intelligible as criticisms of this agent. Insofar as a mental representation can diminish someone's agency by making it out to be lesser or worse, this character's mental representations do so. ${ }^{18}$

The objection we've been considering, then, goes too far. Defenders of doxastic wronging cannot establish a moral asymmetry between belief and credence by filling out the stories that Basu, Schroeder, Marušić, and White tell about doxastic wronging - not, at least, without leading to unattractive results. Thus, the case for wronging credences seems precisely as strong as the case for wronging beliefs.

Of course, radical moral encroachment is not merely a claim about the moral status of doxastic states; it's also a claim about the epistemic status of doxastic states. Recall that Basu and Schroeder draw on two different commitments to defend radical

\footnotetext{
18 To distinguish between this character and more familiar cases of doxastic wronging, one might understand Schroeder's "diminishing an agential contribution" as shorthand for "representing an agent's contribution as insignificant or negative even more strongly than one's evidence does." But this approach rules out other cases of diminishment for which Schroeder's approach is a natural fit. Say, for instance, that you learn that a stranger across the street is very confident (but does not believe), on the basis of your race alone, that you are a thief. You then learn that the stranger's credence matches her flawed, misleading body of evidence about your racial group. It seems entirely appropriate for you to feel diminished by the stranger's judgment.
} 
moral encroachment on belief: first, a commitment to wronging beliefs, and second, a commitment to No Tension for Belief. Similarly, those who think that credences can wrong needn't accept radical moral encroachment on credence unless they endorse a parallel claim:

No Tension for Credence: A credence that morally wrongs someone cannot be an epistemically rational credence.

But, interestingly, No Tension for Credence is precisely as plausible as No Tension for Belief; the reasons for accepting the latter are, equally, reasons for accepting the former. To see why, return to Basu and Schroeder's argument concerning apologies for belief. Basu and Schroeder suggest that, because "I'm sorry I formed that belief, even though it was epistemically rational" is a failed attempt at apology, epistemically rational beliefs cannot morally wrong people. But "I'm sorry I formed this credence, even though it was epistemically rational" is no better an apology than the one that Basu and Schroeder discuss. So No Tension for Credence and No Tension for Belief stand or fall together.

Here is a final argument for premise 2. While it isn't based directly on arguments from proponents of radical moral encroachment, it begins with premises they accept. Suppose we affirm radical moral encroachment on belief. Then one might ask, in cases where the moral encroaches on whether you ought to believe $p$, does the moral encroach on whether you ought to form probabilistic beliefs about $p$ ? Is it okay to flat out believe "my wife has probably started drinking again" or "John Hope Franklin is likely a staff member"? Suppose that, upon seeing John Hope Franklin, the club member believes "this person is more likely to be a valet than any of the white people around him." This strikes us as a paradigm case of racial profiling; if it's objectionably racist to believe "this person is a valet," then it is also objectionably racist to form this probabilistic belief. This provides a good reason for defenders of radical moral encroachment on belief to maintain that there is radical moral encroachment on probabilistic beliefs. However, if we are committed to moral encroachment on probabilistic beliefs, it seems to quickly follow that there can be radical moral encroachment on credences; why would it be morally wrong to believe probably $p$, but morally fine to have a high credence in $p$ ? Thus, via probability-beliefs, we can build a sort of sorites-series from belief that $p$ to high credence in $p$; in each case, it is difficult to see why one attitude would wrong but the other attitude would not.

We've seen, now, that there is quite a bit of dialectical pressure for defenders of radical moral encroachment to treat belief and credence similarly. But this is not the end of the debate over premise (2). Even if nothing in the existing literature about radical moral encroachment vindicates an asymmetrical approach to belief and credence, perhaps there is something that could be said to vindicate that approach. And some will find the search for such a story appealing. Isn't the way I treat someone by believing something of her notably different than the way I treat her when I simply become very confident about one of her traits? We'll now consider attempts to offer a principled story about why radical moral encroachment is limited to belief. 


\subsection{Moral asymmetries between belief and credence?}

We're currently considering an argument centered on the following claim of symmetry between belief and credence:

(2) If there is radical moral encroachment on belief, then there is radical moral encroachment on credence.

In this subsection, we'll consider a family of ways to reject this claim. These strategies aim to establish an asymmetry in the moral profile of belief and credence: to show that credences cannot morally wrong others in the way that beliefs can.

Perhaps the most tempting way to resist (2) is to lean on an insight that we've already considered: that belief involves "ruling out" error-possibilities (or settling the matter, or taking a stand). We've already seen, in Sect. 3.1, why this strategy fails; it's just not plausible that, while a belief-forming racist can wrong others in the way he thinks about them, a slightly cautious racist simply can't.

Another way to argue for asymmetry is to make a claim about control or agency. Perhaps, though we have some measure of control over what we believe, we lack analogous control over credences. And perhaps this explains why, though we can be morally responsible for beliefs, we cannot be morally responsible for credences. This strategy faces an initial hurdle: the orthodox view is that we lack agential control over both beliefs and credences. ${ }^{19}$ But, even if that initial hurdle can be cleared, this strategy for differentiating beliefs and credences is not a promising one. Any grounds that the moral encroacher offers as evidence that we have agential control over beliefs are very likely to be good grounds for thinking that we have agential control over credences as well.

One way to make room for agential control over belief, for instance, is to understand agential control in terms of reasons-responsiveness: I have agential control over a mental state when it is based on reasons in the right sort of way. ${ }^{20}$ But credence, like belief, can be appropriately based on reasons. ${ }^{21}$ A moral encroacher might also attempt to make room for agential control over belief by pointing out the wide diversity of ways in which different people respond to evidence by forming beliefs. Basu and Schroeder (2019: sec. 2), for instance, note that our "needs and interests" can direct our attention, and thereby, can make a difference to which propositions we believe. ${ }^{22}$ They also cite Kruglanski's (2014) psychological research, which suggests that people have a wide variety of "epistemic motivations"-including, in some cases, the motivation to form (or avoid) beliefs in particular propositions. But insofar as this data supports the claim that we have control over our beliefs, similar data also supports the claim that we have

\footnotetext{
19 For a prominent statement of this orthodoxy, see Alston (1988).

20 For the seminal treatment of "rationalizing explanation" of mental states, see Davidson (1963). Floweree (2017) argues that this approach does not rule out agential control over beliefs.

21 A further development of this approach might suggest that we only have agential control over beliefs when our evidence underdetermines the question of whether to believe or withhold—in other words, when we are in a permissive case (see Jackson and Turnbull forthcoming). This move fails to support an asymmetrical approach to belief and credence-many think that permissivism for credence is more plausible than permissivism for belief (see Kelly 2013; Schoenfield 2014; Jackson 2019b).

22 Here, Basu and Schroeder cite Nelson (2010).
} 
control over our credences. There are a wide variety of psychological dispositions that govern credence-revision, and some of these dispositions involve bias in favor of (or against) particular propositions. In brief: we do not see any good reasons for suspecting that the evidence for agential control over doxastic states is evidence solely for agential control over belief.

Let's consider a final strategy for establishing that credences morally differ from beliefs. On this strategy, belief is closely associated with certain dispositions-ones that need not come along with mere credence. ${ }^{23}$ Perhaps, for instance, a person who believes $p$ always has some disposition to take $p$ for granted in practical reasoning, or to assert $p$, whereas a person who is merely very confident that $p$ need not. ${ }^{24}$ And perhaps we can wrong others merely by taking on dispositions of the relevant sort, even if those dispositions never become active.

It's important to distinguish between two ways of developing this view. On the first, dispositions associated with belief are morally problematic insofar as they are dispositions toward morally problematic behavior. When one forms a racist belief, for instance, one may run the risk of taking the wrong action on the basis of that belief-where, if one had suspended judgment, one would not have run a similar risk.

This first approach is a much more natural fit with moderate moral encroachment than with radical moral encroachment. What makes moral encroachment radical is precisely the claim that beliefs can be morally problematic in a way that does not derive from the risk of morally problematic behavior. So, in many of the cases that are used to motivate a distinctively radical sort of moral encroachment in epistemology, a person would not be disposed toward any sort of morally problematic behavior even if she were to form a wronging belief. Consider, for instance, Schroeder's (2018b) example of a Human Resources director whose wrongful belief does not dispose him to morally bad action in any way. In cases of this sort, facts about dispositions to behave cannot explain why belief wrongs in a way that a mere credence could not.

On a second approach, the dispositions that allow beliefs to wrong (while credences cannot) are dispositions toward mental states, not actions. One might argue, for instance, that beliefs come with a disposition toward judging, or toward occurrently believing. ${ }^{25}$ But the radical moral encroacher who takes this second approach simply relocates the explanatory challenge that faces her: what is it about judging, or occurrently believing, that is particularly morally worrisome? This challenge will need to be met by appeal to further points of disanalogy with credence, and likely ones of the sort we've already considered (e.g. the way judging rules out a possibility). In short, allusions to dispositions like judging or occurrently believing do no interesting work, by themselves, to establish a moral difference between belief and credence.

Could allusions to dispositions gain explanatory purchase if coupled with the idea that episodes of judging, or occurrently believing, mentally diminish agential contributions, or amount to taking up the objective stance ${ }^{26}$ We think not. It may well be that judging or occurrently believing something is a distinctive way of relating to her

\footnotetext{
23 Thanks to Alex Worsnip for suggesting this strategy.

${ }^{24}$ Schroeder rejects this claim; see Ross and Schroeder (2014), Schroeder (2018a: sec. 3.1).

25 For the former view, see Smithies (2019: ch. 3); for the latter, see Ross and Schroeder (2014).

26 Thanks to an anonymous referee for encouraging us to say more about this.
} 
mentally, and that beliefs dispose us to take up this distinctive mental relation. We even grant that this might illuminate, by example, how it sometimes feels "from inside" to diminish a person's agential contribution, or to take up the objective stance. But we do not see any reason to think that judging or occurrently believing will be the only such illuminating example. Why couldn't the occurrent phenomenal state associated with being very confident about a person's traits also reveal what it's like, from inside, to relate to her in a problematic way? And the diminishment proposal fares no better here. As our example of a slightly cautious racial profiler shows, even a person who adopts a general policy of suspending judgment about others can still be disposed to occurrently represent them in a way that diminishes their agency.

Let's take stock. In Sect. 3.1, we showed that, to all appearances, credences are just as apt to wrong others as beliefs are. The radical moral encroacher who wishes to deny this initial appearance needs to offer a compelling debunking explanation-one that establishes a clear difference in the moral profile of belief and credence. But there is no such debunking explanation to be found in the current literature. Further, a number of prima facie plausible explanations fail.

\subsection{Asymmetries in encroachment?}

We've now made a case for the claim that, if beliefs can morally wrong, credences can as well. But, even if a defender of radical moral encroachment grants that point, she might nevertheless deny the following premise:

(2) If there is radical moral encroachment on belief, then there is radical moral encroachment on credence.

The way to reject this claim, while granting a moral symmetry between belief and credence, is to argue for a rational asymmetry between belief and credence. In other words, it's to argue that, while norms of epistemic rationality are sensitive to facts about wronging belief, they are insensitive to facts about wronging credences.

The radical moral encroacher who adopts this strategy, however, undercuts the primary motivations for her view. If credences can wrong, but there is no radical moral encroachment on credences, then (as we argued in Sect. 3.1), it's very plausible that certain credences - including ones formed in some cases of racial profiling - are both epistemically rational and morally problematic. But once we acknowledge the possibility of tension between epistemic rationality and morality when it comes to credences, the possibility that the very same tension will arise in the case of belief no longer seems like a serious worry. If we're already committed to the possibility of owing apologies for epistemically rational credences, for instance, it's entirely unclear why we'd worry about the possibility of owing apologies for epistemically rational beliefs. The radical moral encroacher who rejects No Tension for Credence, in other words, should also reject No Tension for Beliefs. But No Tension for Beliefs plays a starring role in the most prominent arguments for radical moral encroachment. Rejecting No Tension for Credence, in other words, forces the radical encroacher back to the drawing board. 
In fact, the situation is even worse: alternate grounds for radical moral encroachment on belief do not seem to be available. One natural place to look for those grounds is the broader literature on pragmatic encroachment in epistemology. That literature includes a host of views on which, although rational credence is not dependent on practical or moral factors, rational belief is so dependent (Fantl and McGrath 2009; Ross and Schroeder 2014). But, remarkably, the literature also leaves wide open the question of whether there is radical moral encroachment in epistemology.

To see this, first note that even if pragmatic encroachment is well-motivated, there are excellent reasons not to accept the extreme view that any practical or moral factor can make a difference to epistemic standards for belief. There are, plausibly, a host of practical and moral factors that (in some broad sense) bear on belief: consider, for instance, moral bribes for believing, promises that put us under moral pressure to believe (Marušić 2013), or friendships that call on us to believe (Keller 2004; Stroud 2006). No one-even defenders of pragmatic encroachment—-takes existing arguments for pragmatic encroachment to adequately support the notion that moral factors like these are among the practical factors that make a difference for epistemic standards.

Second, note that radical moral encroachment represents a remarkable departure from typical defenses of pragmatic encroachment. Typical defenses of pragmatic encroachment aim to establish that, when one meets epistemic standards with respect to $p$, this puts acting on the basis of $p$ beyond the reach of certain practical (and perhaps moral) criticisms. Perhaps, for instance, when one knows that $p$, one's actions cannot be criticized as imprudent (or immoral) on the grounds that one has too little epistemic support for $p$. But no defenses of pragmatic encroachment aim to establish that, when one meets epistemic standards, one's belief itself is beyond the reach of certain practical (or moral) criticisms. And there are good reasons not to defend the latter claim in full generality: defenders of pragmatic encroachment generally do not want to collapse the distinction between epistemically rational belief and belief that it is all-things-considered best to have. ${ }^{27}$

Existing defenses of pragmatic encroachment, then, are the wrong argumentative tools to use in defense of radical moral encroachment. ${ }^{28}$ This is, plausibly, why Basu and Schroeder take it upon themselves to support radical moral encroachment by offering arguments in favor of No Tension for Belief, rather than simply by leaning on Schroeder's antecedent arguments for pragmatic encroachment. But, as we've now seen, once No Tension for Belief is rejected, the only clear line of support for radical moral encroachment on belief evaporates. In short, we do not see any promising ways

\footnotetext{
27 We suspect that Pace's (2011) defense of radical moral encroachment (which differs notably from Basu and Schroeder's) does too little to avoid collapsing this distinction. On Pace's view, merely being offered an adequately strong moral bribe can make it epistemically rational to believe any proposition, so long as one's evidence makes that proposition more likely than not.

28 Schroeder (2018a) suggests that radical moral encroachment on belief is a natural extension of his (2012) account of pragmatic encroachment. But that account is executed in terms of costs of error. This raises two problems. First, some costs of error do not seem to be costs of the right kind to bear on epistemic rationality. For more on this objection, see Worsnip (2020). Second, if wronging beliefs are associated with costs of error, then there must be a distinctive moral badness to false belief. This has unappealing results for the ethics of belief; for more, see Fritz (2019).
} 
to argue in favor of radical moral encroachment on belief without bringing along radical moral encroachment on credence.

\section{Prospects for a belief-credence symmetry}

Recall the main argument we've been discussing:

1. There is radical moral encroachment on belief.

2. If there is radical moral encroachment on belief, then there is radical moral encroachment on credence.

3. Thus, there is radical moral encroachment on credence.

At this point, we've considered and rejected various attempts to deny premise 2 . In this section, we consider what follows from accepting this conditional.

\subsection{Modus ponens}

The first option is to affirm both premise 1 and premise 2 of the argument, and thus accept the conclusion: that there is radical moral encroachment on credence. This is a surprising conclusion, and as far as we know, one with no current defenders.

If one opts for the modus ponens response, they will likely maintain that, in cases where belief in $p$ would morally wrong someone, epistemic rationality forbids believing that $p$ and also forbids forming a high credence that $p$. If your wife comes home with a wine stain on her shirt, for instance, you should continue to have the same attitudes you had before receiving the wine-stain evidence-withholding or disbelieving that she's starting drinking again, and having a low or middling credence. In situations like these, then, rational credence will behave much like rational belief-in some cases, calling for doxastic practices that would otherwise be epistemically questionable, like screening off evidence. This would also mean that in many cases that provide opportunities for, e.g. racial or social profiling, epistemic rationality does not require us to proportion our credences to the statistical evidence; rather, it calls on us to screen off certain pieces of evidence when forming credences (see Freitag and Zinke 2019).

What are reasons one might go in for this kind of picture? An obvious one is that one is antecedently committed to, or convinced by, the arguments for radical moral encroachment on belief. So, holding premise 2 fixed, Basu and Schroeder, for instance, might prefer the modus ponens response. And, for those who find radical moral encroachment attractive, this wholehearted embrace of moral encroachment will have some appealing features. Even when considered apart from beliefs, the cases above seem to involve morally problematic credences. And the defenders of radical moral encroachment are anxious to rule out the possibility that epistemic rationality permits morally problematic doxastic states. 


\subsection{Modus tollens}

But not all will be convinced that credences can wrong. What's more, some will consider radical moral encroachment on credence too extreme to accept. One might find the modus tollens response attractive because in profiling-style cases, moral encroachment on credence seems to require either (1) failing to incorporate evidence about base rates in society altogether, or (2) failing to apply those base rates to particular individuals - which leads to credal probabilistic incoherence. Consider an example. Suppose you know that most (but not all) members of a certain club are white, and most (but not all) staff members are black. Then, for any given individual at the club, it seems to follow that you epistemically ought to have a high credence that they are a staff member, given they are black. But then it seems like if you see a black person at the club (and this is all you know about them), you epistemically ought to have a high credence that they are a staff member. This is just the sort of train of thought that, according to radical moral encroachment on credence, is epistemically irrational in the face of certain moral facts.

Thus, according to radical moral encroachment, epistemic rationality requires you not adopt the high credence supported by your evidence. You could meet this requirement in two ways. First, you could go with (1), and "screen off" your first bit of evidence, i.e. the evidence that $<$ most club members are white and most staff members are black $>$. You could disregard this when forming credences. But this seems epistemically irrational for several reasons, including evidentialist concerns about ignoring pertinent evidence when forming credences, and the fact that your credence in $\mathrm{p}$ fails to match the epistemic probability of $\mathrm{p}$ on your evidence. ${ }^{29}$

Alternatively, you can go with (2), and keep the evidence in mind when forming your credences, but nonetheless form credences about individuals that fail to cohere with that evidence. So, for example, you have a high credence that someone at the club is a staff member, given they are black, but a middling credence that a particular black individual at the club is a staff member. This second option involves a failure of probabilistic coherence, but most epistemologists think probabilistic coherence is necessary for credal rationality. There are a number of reasons to think that incoherent credences are irrational - for example, those with incoherent credences can be Dutch Booked, and for all incoherent credences, there are coherent ones that are a priori guaranteed to be more accurate. ${ }^{30}$ Considerations such as these might push one toward the conclusion that credences (and beliefs!) cannot wrong at all, because radical moral encroachment on credence seems difficult to square with our best theories of epistemic rationality.

There is an alternative view that denies radical moral encroachment, but concedes some things to the encroacher: denying No Tension for both belief and credence. Those who prefer this response affirm that in the cases that motivate moral encroach-

\footnotetext{
29 And as an anonymous referee points out, this could also lead to problematic Moorean sentences such as "my evidence says that p is .9 likely to be true, but I'm not justified in a .9 credence in p." For more on epistemic probability, see Williamson (2000: ch. 10) and Climenhaga (2020).

30 Dutch Book arguments were originally proposed by Ramsey (1926); the accuracy-dominance argument for probabilism was originally proposed by Joyce (1998). For further discussion of the arguments that credences must be probabilistically coherent, see Hájek (2008) and Easwaran (2011).
} 
ment, beliefs and high credences are epistemically rational but morally problematic. If, plausibly, the moral trumps the epistemic in many or all cases of tension (as it generally seems worse to commit a moral offense than to have a false belief; see Jackson 2016: p. 100), then there is both a moral and an all-things-considered reason not to form the attitude in the relevant cases. Thus, one could maintain that the attitudes are problematic in several notable senses, even if they are epistemically rational. While this response denies radical moral encroachment, it nonetheless concedes that there is something seriously wrong with the attitudes formed in the cases of interest. At the same time, it enables us to capture much of what is intuitive behind purism: at least when it comes to certain doxastic states, epistemic rationality is not sensitive to truth-irrelevant factors.

We won't settle on one of these options here. We nonetheless think our argument leaves things a bit awkward for the proponent of radical moral encroachment on belief, as radical moral encroachment on credence is an odd and surprising thesis. Thus, we maintain that radical moral encroachers have a new burden to bear, and we expect this to motivate many to take the modus tollens route.

\section{Conclusion}

We have argued that, when it comes to radical moral encroachment, there is a beliefcredence symmetry: insofar as one accepts radical moral encroachment on belief, one faces pressure to accept radical moral encroachment on credence as well. We've considered and rejected various attempts to resist this symmetry, and outlined implications of accepting the symmetry. We conclude that radical moral encroachers have good reason to think that both belief and credence are subject to encroachment, and purists about credence have good reason to reject radical moral encroachment altogether.

Acknowledgements Thanks to Ethan Brauer, Daniel Wilkenfeld, Tristram McPherson, Joshua Smart, Nevin Climenhaga, and anonymous referees at Synthese for helpful comments on earlier drafts. Research on this paper was supported by Australian Research Council Grant D170101394.

Authors' contribution James Fritz and Elizabeth Jackson contributed equally to this article, and were equally involved in every stage of its conception and writing.

\section{References}

Alston, W. (1988). The deontological conception of epistemic justification. Philosophical Perspectives, 2, 257-299.

Basu, R. (2019a). What we epistemically owe to each other. Philosophical Studies, 176, 915-931.

Basu, R. (2019b). The wrong of racist beliefs. Philosophical Studies, 176(9), 2497-2515.

Basu, R., \& Schroeder, M. (2019). Doxastic wronging. In B. Kim \& M. McGrath(Eds.), Pragmatic encroachment in epistemology. New York: Routledge.

Bolinger, R. J. (2020). The rational impermissibility of accepting (some) racial generalizations. Synthese, 197, 2415-2431.

Bolinger, R. J. (Forthcoming). Varieties of moral encroachment. Philosophical Perspectives. https://doi. org/10.1111/phpe.12124.

Buchak, L. (2014). Belief, credence, and norms. Philosophical Studies, 169(2), 285-311. 
Churchland, P. M. (1981). Eliminative materialism and the propositional attitudes. Journal of Philosophy, 78, 67-90.

Clifford, W. K. (1886). In L. Stephen \& F. Pollock (Eds.), The ethics of belief (pp. 339-363) London: Macmillan and Co.

Climenhaga, N. (2020). The structure of epistemic probabilities. Philosophical Studies, 77(11), 1-30.

Davidson, D. (1963). Actions, reasons, and causes. The Journal of Philosophy, 60(23), 685-700.

Easwaran, K. (2011). Bayesian I: Introduction and arguments in favor. Philosophy Compass, 6(5), 312-320.

Enoch, D., \& Spectre, L. (Ms). Statistical Resentment.

Fantl, J., \& McGrath, M. (2009). Knowledge in an uncertain world. Oxford: Oxford University Press.

Floweree, A. K. (2017). Agency of belief and intention. Synthese, 194(8), 2763-2784.

Freitag, W., \& Zinke, A. (2019). Statistics and suspension. Philosophical Studies. https://doi.org/10.1007/ s11098-019-01344-7.

Fritz, J. (2017). Pragmatic encroachment and moral encroachment. Pacific Philosophical Quarterly, 98(1), 643-661.

Fritz, J. (2019). Moral encroachment and reasons of the wrong kind. Philosophical Studies. https://doi.org/ 10.1007/s11098-019-01359-0.

Gao, J. (2019). Credal pragmatism. Philosophical Studies, 176(6), 1595-1617.

Gardiner, G. (2018). Evidentialism and moral encroachment. In K. McCain (Ed.), Believing in accordance with the evidence: New essays on evidentialism (pp. 169-195). Cham: Springer.

Gardiner, G. (2020). Relevance and risk: How the relevant alternatives framework models the epistemology of risk. Synthese. https://doi.org/10.1007/s11229-020-02668-2.

Gendler, T. (2011). On the epistemic costs of implicit bias. Philosophical Studies, 156(1), 33-63.

Hájek, A. (2008). Arguments for-or against-probabilism? The British Journal for the Philosophy of Science, 59(4), 793-819.

Hawthorne, J., \& Stanley, J. (2008). Knowledge and action. The Journal of Philosophy, 105(10), 571-590.

Jackson, E. (2016). Wagering against divine hiddenness. The European Journal for Philosophy of Religion, $8(4), 85-108$.

Jackson, E. (2019a). How belief-credence dualism explains away pragmatic encroachment. The Philosophical Quarterly, 69(276), 511-533.

Jackson, E. (2019b). Belief and credence: Why the attitude-type matters. Philosophical Studies, 176(9), $2477-2496$.

Jackson, E. (2020). The relationship between belief and credence. Philosophy Compass, 15(6), 1-13.

Jackson, E., \& Turnbull, M. G. (Forthcoming). Permissivism, underdetermination, and evidence. In C. Littlejohn \& M. Lasonen-Aarnio (Eds.), The Routledge handbook for the philosophy of evidence. New York: Routledge.

Joyce, J. (1998). A nonpragmatic vindication of probabilism. Philosophy of Science, 65, 575-603.

Keller, S. (2004). Friendship and belief. Philosophical Papers, 33(3), 329-351.

Kelly, T. (2013). Evidence can be permissive. In M. Steup, J. Turri, \& E. Sosa (Eds.), Contemporary debates in epistemology (2nd ed., pp. 298-311). Hoboken: Wiley.

Kruglanski, A. (2014). The psychology of closed mindedness. New York: Psychology Press.

Maher, P. (1993). Betting on theories. Cambridge: CUP.

Marušić, B. (2013). Promising against the evidence. Ethics, 123, 292-317.

Marušić, B., \& White, S. (2018). How can beliefs wrong?-A Strawsonian epistemology. Philosophical Topics, 46(1), 97-114.

Moss, S. (2018a). Probabilistic knowledge. Oxford: OUP.

Moss, S. (2018b). Moral encroachment. The Proceedings of the Aristotelian Society, 118(2), 177-205.

Nagel, J. (2010). Epistemic anxiety and adaptive invariantism. Philosophical Perspectives, 24(1), 407-435.

Nelson, M. (2010). We have no positive epistemic duties. Mind, 119(1), 83-102.

Pace, M. (2011). The epistemic value of moral considerations: Justification, moral encroachment, and James' "will to believe". Noûs, 45(2), 239-268.

Ramsey, F. (1926). Truth and probability. In Ramsey, 1931, The foundations of mathematics and other logical essays, Ch. VII, pp. 156-198, edited by R.B. Braithwaite, London: Kegan, Paul, Trench, Trubner \& Co., New York: Harcourt, Brace and Company.

Roeber, B. (2018). Anti-intellectualism. Mind, 127(506), 437-466.

Ross, J., \& Schroeder, M. (2014). Belief, credence, and pragmatic encroachment. Philosophy and Phenomenological Research, 88(2), 259-288. 
Schoenfield, M. (2014). Permission to believe: Why permissivism is true and what it tells us about irrelevant influences on belief. Noûs, 48, 193-218.

Schroeder, M. (2012). Stakes, withholding, and pragmatic encroachment on knowledge. Philosophical Studies, 160(2), 265-285.

Schroeder, M. (2018a). Rational stability under pragmatic encroachment. Episteme, 15(3), 297-312.

Schroeder, M. (2018b). When beliefs wrong. Philosophical Topics, 46(1), 115-127.

Schroeder, M. (2019). Persons as things. In M. Timmons (Ed.), Oxford studies in normative ethics (Vol. 9, pp. 95-115). Oxford: Oxford University Press.

Schwitzgebel, E. (2019). Belief. Stanford Encyclopedia of Philosophy. Retrieved July 22, 2020 from http:// plato.stanford.edu/entries/belief/.

Staffel, J. (2017). Accuracy for believers. Episteme, 14(1), 39-48.

Staffel, J. (2019). How do beliefs simplify reasoning? Nô̂s, 53(4), 937-962.

Stanley, J. (2005). Knowledge and practical interests. Oxford: OUP.

Stich, S. (1996). Deconstructing the mind. Oxford: OUP.

Strawson, P. F. (1962/2008). Freedom and resentment. In Freedom and resentment and other essays. London: Routledge.

Stroud, S. (2006). Epistemic partiality in friendship. Ethics, 116(3), 498-524.

Williamson, T. (2000). Knowledge and its limits. Oxford: OUP.

Worsnip, A. (2020). Can pragmatists be moderate? Philosophy and Phenomenological Research. https:// doi.org/10.1111/phpr.12673.

Publisher's Note Springer Nature remains neutral with regard to jurisdictional claims in published maps and institutional affiliations. 